\title{
Investigation of Top/bottom Electrode and Diffusion Barrier Layer for PZT thick film MEMS Sensors
}

\author{
Pedersen, Thomas; Hindrichsen, Christian Carstensen; Lou-Møller, R.; Thomsen, Erik Vilain
}

Published in:

Proceedings of IEEE Sensors 2007

Link to article, DOI:

10.1109/ICSENS.2007.4388510

Publication date:

2007

Document Version

Publisher's PDF, also known as Version of record

Link back to DTU Orbit

Citation (APA):

Pedersen, T., Hindrichsen, C. C., Lou-Møller, R., \& Thomsen, E. V. (2007). Investigation of Top/bottom Electrode and Diffusion Barrier Layer for PZT thick film MEMS Sensors. In Proceedings of IEEE Sensors 2007 (pp. 756-759). IEEE. https://doi.org/10.1109/ICSENS.2007.4388510

\section{General rights}

Copyright and moral rights for the publications made accessible in the public portal are retained by the authors and/or other copyright owners and it is a condition of accessing publications that users recognise and abide by the legal requirements associated with these rights.

- Users may download and print one copy of any publication from the public portal for the purpose of private study or research.

- You may not further distribute the material or use it for any profit-making activity or commercial gain

- You may freely distribute the URL identifying the publication in the public portal 


\title{
Investigation of Top/Bottom Electrode and Diffusion Barrier Layer for PZT Thick Film MEMS Sensors
}

\author{
T. Pedersen, C. C. Hindrichsen and E. V. Thomsen \\ Department of Micro and Nanotechnology (MIC) \\ Technical University of Denmark (DTU) \\ Lyngby, Denmark \\ tpe@mic.dtu.dk
}

\author{
K. Hansen \\ Ferroperm Piezoceramics A/S \\ Kvistgaard, Denmark
}

\author{
R. Lou-Møller \\ InSensor A/S \\ Kvistgaard, Denmark
}

\begin{abstract}
In this work screen printed piezoelectric Ferroperm PZ26 lead zirconate titanate (PZT) thick film is used for two MEMS devices. A test structure is used to investigate several aspects regarding bottom and top electrodes. $450 \mathrm{~nm} \mathrm{ZrO}_{2}$ thin film is found to be an insufficient diffusion barrier layer for thick film PZT sintered at $850^{\circ} \mathrm{C}$. E-beam evaporated $\mathrm{Al}$ and Pt is patterned on PZT with a lift-off process with a line width down to $3 \mu \mathrm{m}$. The roughness of the PZT is found to have a strong influence on the conductance of the top electrode.
\end{abstract}

\section{INTRODUCTION}

Micro-electromechanical systems (MEMS) utilizing the piezoelectric effect have gained increasing attention lately. The purpose of this paper is to investigate bottom and top electrode formation for MEMS devices utilizing the piezoelectric effect of screen printed $\mathrm{Pb}\left(\mathrm{Zr}_{\mathrm{x}} \mathrm{Ti}_{1-\mathrm{x}}\right) \mathrm{O}_{3}(\mathrm{PZT})$ materials.

Fig. 1 shows a schematic drawing of the two devices of interest, a) a tri-axial accelerometer [1] and b) a piezoelectric Micromachined Ultrasonic Transducer (pMUT). Beams or membranes are created by a deep plasma etch and SOI wafers are used to ensure a uniform beam or membrane thickness. For both device designs high resolution patterning of the top and bottom electrodes are crucial. The electrode thickness has an influence on the mechanical properties of the MEMS device and should be minimized.

PZT thick films have a high coupling factor and shows small temperature dependence. Screen printing of PZT on Si substrates [1] has shown promising results and thicker films are obtainable compared to the sol-gel thin film technique. Thick films result in higher sensitivity and are preferred for
MEMS accelerometers and pMUT scan heads utilizing the $\mathrm{d}_{31}$ mode. Screen printing of PZT results in new fabrication challenges with respect to the electrodes compared to thin film processing $[2,3]$.

Thick film PZT requires a high sintering temperature of at least $850^{\circ} \mathrm{C}$ and a better diffusion barrier layer between $\mathrm{Si}$ and the PZT is therefore needed compared to thin film PZT. $\mathrm{Ti} / \mathrm{Pt}$ is a good conducting diffusion barrier layer [2]. For the device designs shown in Fig. 1 an insulating barrier layer is preferred as it allows patterning of the bottom electrode. $\mathrm{ZrO}_{2}$ has successfully been used for thin film PZT [3] and is tested for screen printed PZT in this paper. It is important to note that the type of PZT used in this work is PZ26 from Ferroperm Piezoceramics A/S. PZ26 is a hard doped PZT material.

Patterning of the top electrode using an etch-back of the metal is challenging as the properties of the PZT typically also are affected [4], thus a lift-off based technique is employed in this work. A rougher PZT surface due to the larger grain size of thick films demands a good top electrode coverage. A comparison is made between the resolutions of a screen printed $\mathrm{Au}$ top electrode and an e-beam evaporated top electrode patterned with a lift-off process. Both $\mathrm{Al}$ and Pt are tested with the lift-off approach and compared with respect to the deposition process and material properties. Screen printed top electrodes are in the range of a few micrometers [5] where e-beam evaporated are in the range of a few hundred nanometers. The optimal thickness of the latter is found by introducing a roughness factor indicating the change in conductance due to the roughness of the PZT surface. 
a)

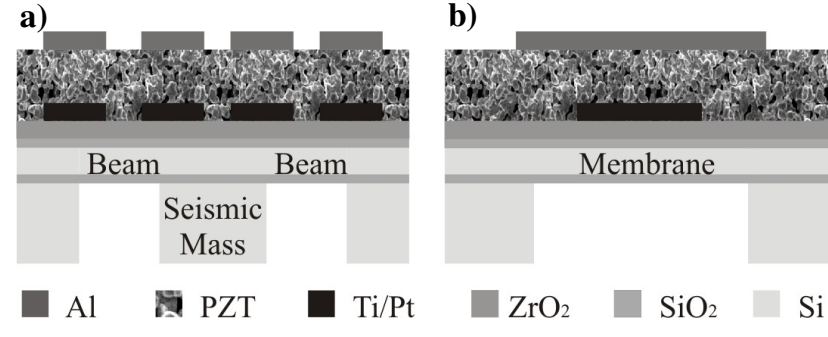

Figure 1. a) Schematic of an accelerometer with a seismic mass suspended by two beams. b) Schematic of a pMUT with PZT thick film and patterned top and bottom electrode.

\section{BOTTOM ELECTRODE}

In order to create a patterned bottom electrode it is necessary to coat the silicon substrate with an insulating diffusion barrier layer. If no barrier layer is present, interdiffusion of $\mathrm{Pb}$ and $\mathrm{Si}$ will destroy the piezoelectric properties of the PZT. Previously it has been reported that $60 \mathrm{~nm}$ of $\mathrm{ZrO}_{2}$ is a functional diffusion barrier layer for PZT thin films sintered at $700^{\circ} \mathrm{C}$ [3]. Thus it is attempted to use a $\mathrm{ZrO}_{2}$ film for PZT thick films. The $\mathrm{ZrO}_{2}$ film is deposited by a sol-gel spin on method. The precursor sol is made of zirconium n-propoxide stabilized by acetylacetone and dissolved in isopropanol. Several layers are spun on $\mathrm{Si}$ wafers at 3000 RPM with intermediate baking steps at $350^{\circ} \mathrm{C}$ before the final anneal at $900^{\circ} \mathrm{C}$. Up to 10 layers have been deposited for a total thickness of $450 \mathrm{~nm}$, the $\mathrm{ZrO}_{2}$ layer is deposited on top of a $500 \mathrm{~nm} \mathrm{SiO}$ layer. This has however proven to be insufficient as a diffusion barrier layer. The most likely reason is that the high sintering temperature of $850^{\circ} \mathrm{C}$ for one hour causes a diffusion of $\mathrm{Pb}$ and $\mathrm{Si}$ across the $\mathrm{ZrO}_{2}$ layer. As no insulating diffusion barrier layer has been found the focus of this work is on the top electrode.

\section{TOP ELECTRODE}

Top electrodes are formed both by screen printing and by e-beam evaporation followed by lift-off. As the evaporated metal layers have a thickness down to $100 \mathrm{~nm}$ the roughness of the PZT becomes of great importance.

\section{A. PZT Roughness}

The PZT layer is screen printed on $\mathrm{Si}$ substrates with a $\mathrm{SiO}_{2}$ ITilPt layer with a thickness of $500|50| 500 \mathrm{~nm}$, this serves as a diffusion barrier layer and bottom electrode. The PZT is screen printed through a $77 \mathrm{~T}$ polyester mesh mask which has 77 lines per inch (30 lines per centimeter). The wires in the mask are $70 \mu \mathrm{m}$ thick. The roughness of the screen printed PZT is evaluated with a Tencor P-1 stylus profiler. A typical scan of a $30 \mu \mathrm{m}$ thick screen printed PZT layer is seen in Fig. 2. The large features separated a few hundred micrometers is due to the wires in the polyester mesh mask. The RMS roughness is measured to be $1.6 \mu \mathrm{m}$ based on $5 \mathrm{~mm}$ long scans. This roughness is higher than for typical PZT thin films and thus it is more difficult to do planar processing on thick film PZT compared with thin film PZT.

\section{B. Metal Deposition Techniques}

Metallization for the top electrode can be done by screen printing a gold paste through a mask. This technique has a resolution of roughly $100 \mu \mathrm{m}$ and a metal thickness of 5-10 $\mu \mathrm{m}$. The roughness is even greater than the underlying PZT, see Fig. 3. Electrical connectors with a line width of $100 \mu \mathrm{m}$ creates large parasitic capacitances, and the thick screen printed electrode has a large influence on the mechanical behavior of the device; this influence is diminished by making a thinner e-beam evaporated top electrode.

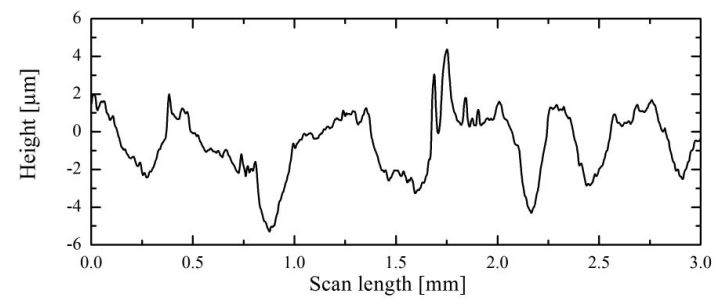

Figure 2. Stylus profiler scan of a screen printed PZT layer with a thickness of $30 \mu \mathrm{m}$. The RMS roughness is calculated from such scans to be $1.6 \mu \mathrm{m}$.

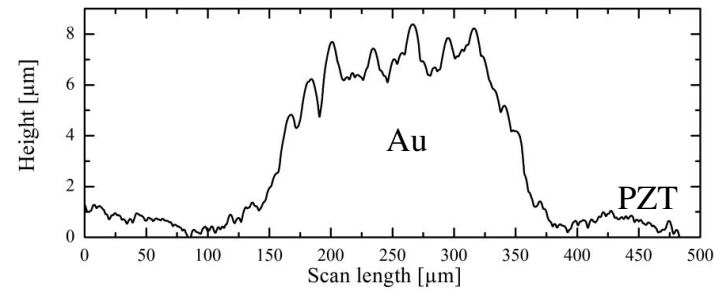

Figure 3. Profile scan of a $200 \mu \mathrm{m}$ wide screenprinted Au electrode. The roughness of the electrode is greater than the underlying PZT.

E-beam evaporation is done in a Wordentec QCL800 Metal Evaporator. The deposited metal is patterned with a lift-off technique. Both $\mathrm{Pt}$ and $\mathrm{Al}$ are tested as top electrode materials. Lift-off of metal is usually done with a negative tone photoresist due to the inward sloping profile, but can be difficult to control when using a thick $(\sim 5 \mu \mathrm{m})$ resist. In this case, the resist has to be thick enough to cover the roughness of the PZT layer. Thus, also a thicker, positive tone photoresist is tested. The negative resist has a thickness of $4.2 \mu \mathrm{m}$ and the positive resist has a thickness of $9.5 \mu \mathrm{m}$. As positive resist, AZ4562 is used and as a negative resist AZ5214E Image Reversal resist is used.

Previously adhesion problems have been reported when immersing the PZT in photoresist developer (Microposit MF322), resulting in the PZT to peel off [4]. In our case a AZ351B developer does not seem to affect the PZT.

It proved to be difficult to lift off the metal from the negative process, requiring significantly more ultrasonic agitation than when using the positive process. It is believed that the thinner negative tone resist is not thick enough to effectively cover the PZT surface during metal deposition. 
The best results are obtained when using a positive lithography process, even though the resist profile has outward sloping sidewalls. The metal covers most of the sloped sidewall of the photoresist but there is a small gap for the acetone to penetrate, see Fig. 4. With the positive lithography process it has been possible to produce $3 \mu \mathrm{m}$ wide $\mathrm{Al}$ wires with a thickness down to $100 \mathrm{~nm}$ and a length of $20 \mathrm{~mm}$ on $30 \mu \mathrm{m}$ thick PZT layers, see Fig. 5.

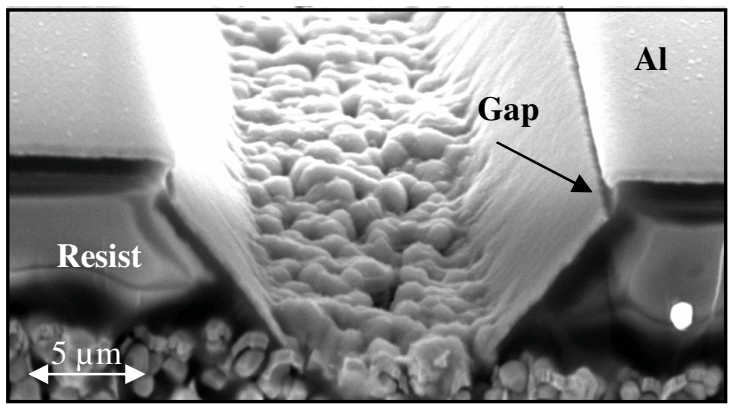

Figure 4. SEM image of a patterned, positive tone photoresist on PZT with $500 \mathrm{~nm} \mathrm{Al}$ deposited on the photoresist for lift-off. The metal is seen to cover most of the sloped sidewall of the photoresist.

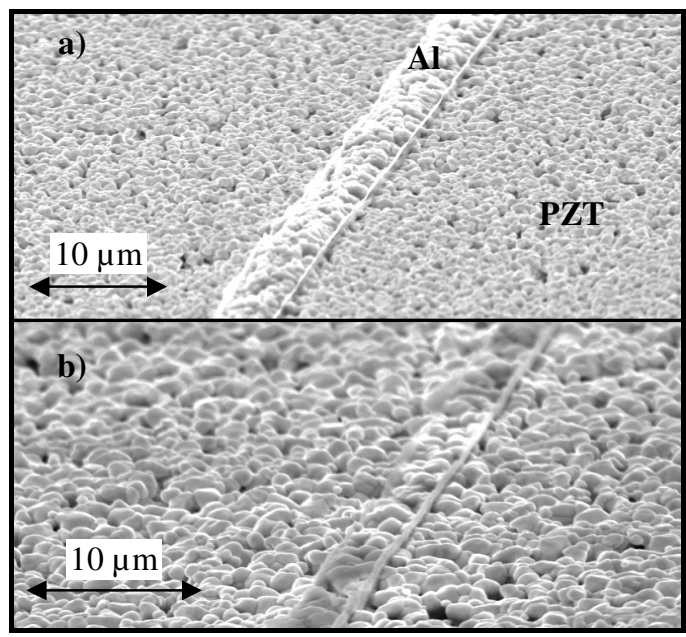

Figure 5. SEM images of a $1000 \mathrm{~nm}$ (a) and $200 \mathrm{~nm}$ (b) thick Al top electrode on PZT thick film fabricated with a lift-off process. Line widths down to $3 \mu \mathrm{m}$ have successfully been fabricated on the rough PZT surface.

A direct comparison between the results from the positive and the negative process are seen in Fig. 6. Here microscope images of a $20 \mu \mathrm{m}$ wide Pt wire from both a positive and a negative process are shown. It is clear that the line definition is better from the positive process. The poor line definition from the negative process is most likely an effect from the coverage problems of the resist because it is too thin compared to the roughness of the PZT.

After deposition of $\mathrm{Pt}$ the resist would often appear to have developed cracks. This is believed to be due to poor thermal conduction of the relatively thick photoresist and PZT layer. This sort of damage to the resist has not been seen when depositing $\mathrm{Al}$, which has a significantly lower melting point than $\mathrm{Pt}$ and thus transfers less heat to the substrate during deposition. With regards to top electrode deposition $\mathrm{Al}$ is found to be better than $\mathrm{Pt}$.

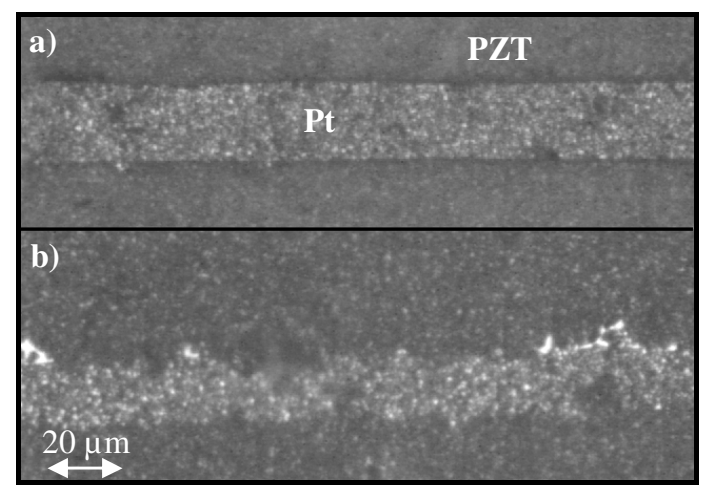

Figure 6. Comparison of $20 \mu \mathrm{m}$ wide Pt wires fabricated on PZT with a) positive and $b$ ) negative tone photoresist.

\section{TOP ELECTRODE THICKNESS}

The optimal thickness of the top electrode is a compromise between good conductance and low mechanical influence. In order to quantify the conductance of the lift-off top electrode a test mask with wire length, $l$, ranging from 1 $\mathrm{mm}$ to $20 \mathrm{~mm}$ and wire width, $w$, from $3 \mu \mathrm{m}$ to $100 \mu \mathrm{m}$ are used.

The resistance, $R$, of a wire deposited on the PZT will be greater than the resistance of a similar wire on a flat substrate due to the roughness of the surface. This increase compared with an equivalent wire on a smooth surface relates how the roughness affects the conductance of the top electrode. The resistance of a long and narrow wire on the PZT surface is given by,

$$
R=x \frac{\rho l}{w h}
$$

where $\rho$ and $h$ are the resistivity of the metal and the top electrode thickness respectively. The change of resistance due to the roughness of the PZT surface is expressed by the roughness factor, $x$.

As the top electrode thickness decreases, the roughness of the PZT has a larger impact on resistance and the roughness factor increases. For increasing top electrode thickness the roughness factor goes asymptotically to one. A roughness factor of one corresponds to a perfect wire on a completely smooth surface. Both Pt and Al are tested as top electrode materials.

Wires with thicknesses ranging from $100 \mathrm{~nm}$ to $1000 \mathrm{~nm}$ are deposited. Fig. 7 shows the resistance as a function of the inverse wire width for four different thicknesses of $\mathrm{Al}$ wires. The good linear fits $(\mathrm{R}>0.98)$ indicate the expected ohmic behavior of the wires. 


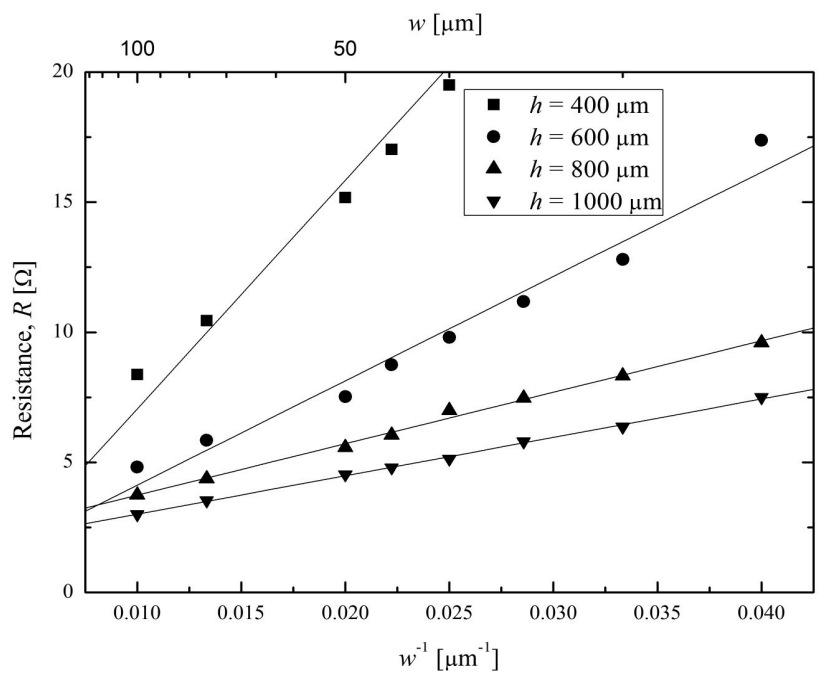

Figure 7. Resistance as a fucntion of the inverse wire width, $w^{-1}$, is shown for different $\mathrm{Al}$ top electrode thicknesses, $h$. A linear, ohmic behavior is seen and the roughness factor is a function of the slope of the linear fits.

The roughness factor is given as a function of the slope of the lines in Fig. 7. The roughness factor is decreasing as a function of thickness as expected, see Fig. 8. A thickness of $100 \mathrm{~nm}$ gives a roughness factor of 4.6 which means that the electrode is 4.6 times less conducting compared to an electrode on a smooth surface. The roughness factor should theoretically be independent of the electrode material although Fig. 8 generally shows a slightly higher value for $\mathrm{Pt}$ compared with Al. This is presumably related to the difficulties in the lift-off process of $\mathrm{Pt}$ as explained earlier.

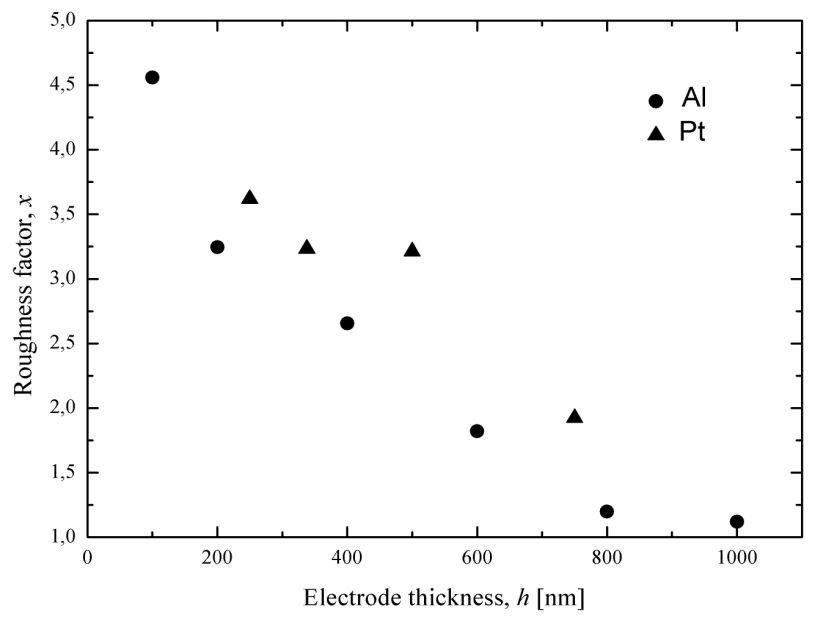

Figure 8. Roughness factor, $x$, as a function of metal thickness for thicknesses between 100 and $1000 \mathrm{~nm}$.

As demonstrated, the resistance of wires deposited on PZT is not simply linearly dependent on metal thickness due to the roughness of the PZT, so this aspect has to be considered when designing PZT thick film based devices.

Increasing the electrode thickness has a negative effect on the mechanical behavior of the MEMS devices. For instance, a top electrode with a thickness of $600 \mathrm{~nm}$ on a Si beam with a thickness of $40 \mu \mathrm{m}$ in an accelerometer design as shown in Fig. 1, results in an decrease in beam deflection of $2.4 \%$ and $5.7 \%$ for $\mathrm{Al}$ and $\mathrm{Pt}$, respectively. The effect on the mechanical behavior can therefore not be neglected.

A top electrode thickness of $600 \mathrm{~nm}$ seems very high compared to what have been presented previously [2] but as Fig. 8 shows, the high surface roughness demands thicker top electrodes. As long as the top electrode is deposited after the sintering process almost all metals are candidates. At first $\mathrm{Al}$ seems to be preferable compared with Pt due to the lower Young's modulus and less influence on the mechanical behavior. For piezoelectric MEMS devices with a sandwich structure of different layers (see Fig. 1) the coefficients of thermal expansion, CTE, should also be considered. $\mathrm{Al}$ and Pt have $24 \mu \mathrm{m} /\left(\mathrm{m}^{\circ} \mathrm{C}\right)$ and $9.2 \mu \mathrm{m} /\left(\mathrm{m}^{\circ} \mathrm{C}\right)$ respectively and $\mathrm{Si}$ and PZT have $2.6 \mu \mathrm{m} /\left(\mathrm{m}^{\circ} \mathrm{C}\right)$ and $2.0 \mu \mathrm{m} /\left(\mathrm{m}^{\circ} \mathrm{C}\right)$, respectively. Considering the $C T E, \mathrm{Pt}$ is the preferred choice.

\section{CONCLUSION}

Using screen printed PZT thick films instead of thin films results in more crtitical fabrication processes of both the bottom and top electrodes. In order to pattern the bottom electrode $450 \mathrm{~nm} \mathrm{ZrO}_{2}$ as an insulating diffusion barrier layer is found to be isufficient for screen printed PZT. Al and $\mathrm{Pt}$ are tested as top electrode materials which both have advantages and disadvantages. A factor describing the decrease in conductance of the top electrode due to the surface roughness is introduced.

\section{ACKNOWLEDGMENT}

This work is a result of the PiMEMS project which is a collaboration between MIC, InSensor A/S and Ferroperm Piezoceramics A/S and is supported by "The Danish National Advanced Technology Foundation”.

\section{REFERENCES}

[1] R. Lou-Møller, C. C. Hindrichsen, L. H. Thamprup, T. Bove, E. Ringgaard, A. F. Pedersen, "Screen-printed piezoceramics thick films for miniaturised devices,", J. Electroceramics, 2007 (in press).

[2] Zhinhong Wang, Weiguang Zhu, Jianmin Miao, Hong Zhu, Chen Chao, Ooi Kiang Tan, "Micromachined thick film piezoelectric ultrasonic transducers array", S. Actuators A, 130-131, 2006, p. 485490.

[3] F. F. C. Duval, R. A. Dorey, R. W. Wright, Z. Huang, R. W. Whatmore, "Fabrication and Modeling of High-Frequency PZT Composite Thick Film Membrane Resonators", IEEE Transactions on Ultrasonics, vol. 51, nr. 10, 2004, p. 1255-1261.

[4] S. P. Beeby, A. Blackburn, N. M. White, "Processing of PZT piezoelectric thick films on silicon for microelectromechanical systems", J. Micromechanical. Microeng. 9 (1999), p. 218-229

[5] S. P. Beeby, N. J. Grabham, N. M. White, "Microprocessor implemented self-validation of thick-film PZT/silicon accelerometer", S. Actuators A, 92 (2001), 168-174 